\title{
Students' Attitudes Toward Peer Feedback: Paving a Way for Students' English Writing Improvement
}

\author{
Sirikarn Kuyyogsuy ${ }^{1}$ \\ ${ }^{1}$ Graduate School of Human Sciences, Assumption University of Thailand, Thailand \\ Correspondence: Sirikarn Kuyyogsuy, Graduate School of Human Sciences, Assumption University, Thailand.
}

Received: April 7, 2019 Accepted: June 16, 2019 Online Published: June 18, 2019

doi: 10.5539/elt.v12n7p107 URL: https://doi.org/10.5539/elt.v12n7p107

\begin{abstract}
This study aimed at exploring students' attitudes toward peer feedback to develop their English writing ability. A mixed methods research, an embedded experimental design, was adopted to elicit students' viewpoints toward peer feedback making use of five-point Likert scale questionnaires comprising 36 statements and six open-ended questions, which were conducted to 21 undergraduate students majoring in English in one university in the three Southern border provinces of Thailand. For the data analysis, A paired samples t-test was quantitatively analyzed, wherereas content themantic analysis was adopted for qualitative data. The overall findings illustrated that the students had a positive attitude toward using peer feedback that achieved a high level in four domains in terms of the writing process, affective strategies, critical thinking skills and social interaction ability. From the result, it could also be seen that students understood about the writing strategy and were able to conduct peer feedback process more effectively, produced improved writing performance with better grammar structure. Additionally, discussing by peers evevated critical thinking skills and developed social skills through working collaboratively. Importantly, peer feedback process supports a student-centered approach and allows students to become more autonomous learners in writing. Consequently, peer feedback should be taken into consideration in the curricula of L2 writing.
\end{abstract}

Keywords: peer feedback, attitudes, L2 writing

\section{Introduction}

Peer feedback has been regarded as a crucial feedback delivery system in process-based L2 writing classes, and it has been widely considered as an effective approach to facilitate teachers for students' writing improvement (Rollinson, 2005). Many studies have confirmed the positive effects of peer feedback toward the development of ESL/EFL writing contexts and students' language acquisition (K. Hyland \& F. Hyland, 2006). In particular, the implementation of peer feedback in educational settings has become a popular area for research in the L2 writing context, and peer feedback is determined as an interactive learning process, which learners engage in dialogues in relation to their performance and standard (Lie \& Carless, 2006). Peer feedback has been highlighted about learners' substantial potential; for example, peer feedback helps decrease students' writing anxiety, improves a sense of audience, and increases fluency (Stanley, 1992). Moreover, students' improvement of writing can be developed through peer correction (Hyland, 2000), and engaging in the group increases their self-confidence and self- motivation in learning. Furthermore, it assists students to supplement their critical and analytical thinking and self-awareness of effective writing skills as means by providing critical and constructive comments. The student readers make their efforts and take into account their clarifications and explanations. Therefore, written commentary and revision provides students with more opportunities in developing the criteria for evaluation and becoming a critical reader (Rollinson, 2005). In addition, students' metacognitive awareness is activated; it also provides learner autonomy (Mendoca \& Johnson, 1994). Notably, students' social skills are more increasingly supported in peer interaction. Nevertheless, although some studies have reported the factors in conducting peer feedback such as being a time-consuming activity and laborious process, requiring pre-training and the lengthy instructions and the quality of providing and recieving feedback compared to teacher feedback (Legi, 1991; Ferris, 2003; Gielen et al., 2010 as cited in Bosboom et al..2014), various studies have focused on the potential that peer feedback has proved to be an effective pedagogical approach to improve students' writing competence in L2 writing classes (Corbin, 2012). According to the Thai educational system, it has been emphasized the teacher-centered method, which is primarily dominated by teachers' roles; moreover, this phenomenon produces 
the regular spoon-feeding teaching style and strictness of the teachers' process. To maximise students' learning motivation, peer feedback is one of the potential ways that can be adopted to improve students' writing ability. Consequently, the researcher believes that peer feedback plays a pivotal role in motivating students' participation in L2 writing because of its fruitful potential in developing their writing competence. Accordingly, the present study aimed to investigate students' attitudes toward peer feedback in the L2 writing of Thai university students. Importantly, it was expected that the current study would provide more insight into their viewpoints toward the use of peer feedback in an L2 writing class. Therefore, the research question emphasized the students' attitudes toward utilizing peer feedback in developing their writing ability.

\section{Literature Review}

\subsection{Peer Feedback}

Peer feedback has been widely employed in teaching ESL/EFL writing since the late 1980s (Berg, 1999) as part of the process-oriented instruction of which the emphasis is on the process writing approach. Peer feedback is referred to as peer review, peer response, peer editing, peer critiquing and peer evaluation that has been defined as a collaborative activity in which students read, discuss and provide information on other compositions to improve their writing ability through mutual scaffolding (Hu, 2005; Konwonse, 2013; Nguyen, 2016; Tsui \& Ng, 2000; Zhu, 2001). This also corresponds with Liu and Hansen's (2002) study, which reported that peer feedback actively involve students to the activity of collaboratively forming pairs or groups by providing information on one another's written tasks through the oral and written formats with each other's progress over multiple drafts. Hence, peer feedback is perceived as a powerful constructivist tool to enrich learning and teaching undertaken by the teacher, and/or by the students, which provides information to be adopted as feedback to modify the activities in which they get involved (Black and William, 1998a; Marzano, 2007 as cited in Rahmat, 2013).

\subsection{Advantages and Disadvantages of Peer Feedback Toward Teaching and Learning}

Research has revealed that peer feedback can be valued as an effective hands-on learning experience because it helps increase students' writing ability by means of allowing them to play the role of the authors and reviewers whose task is to provide feedback to their peers' compositions (Hansen \& Liu, 2005; Lam, 2010). Moreover, peer feedback is believed to be useful and helpful to students in writing, for it is timely and more informative, which crucial components for their active engagement in offering feedback given to them a voice in scaffolding and constructing their own ability and eventually sharing what they think (Lu \& Law, 2012; Reynolds, 2009). In particular, various researchers of L2 writing (Hu, 2005; Lam; 2010; Min, 2016) have emphasized the importance of peer feedback in providing the potential of developing students' learning. For instance, peer feedback practice provides students with multiple sources of constructive and supportive feedback; the recursive process of peer feedback also raises self-awareness, builds confidence, increases motivation, boosts critical thinking skills and supports students' social abilities (Farrah, 2012; Hirose, 2008; Orsmond et al., 2013). Additionally, students can progressively develop autonomous learning and achieve higher levels of critical thinking (Brusa \& Harutyunyan, 2019).

In spite of the perceived benefits, several studies have reported that there were still some negative perspectives toward the use of peer feedback. For example, Rollinson (2005) mentioned that the peer feedback activity is so time-consuming when the learners are not familiar with the process because the process is very length such as reading and taking notes, collaborating with another reader to reach a consensus, and give a written commentary, or being involved orally with the writer that consumes a significant amount of time. Most of all, students' failure of conducting peer feedback may be due to the fact that the feedback conveyed makes the student writer feel frustrated when the student readers deliver their information. These issues were caused by peer feedback training (Min, 2005), time limitations (Legi, 1991) and the qualified feedback and credibility on peer response (Torwong, 2003). As a result, intensive peer training is imperative to practice students to become qualified informants in both providing and receiving feedback on the critique of the compositions. Additionally, the significance of peer feedback has intensely focused on L2 learning theories by changing communicative language teaching and the process approach to writing by shifting the teacher-centered approach into a student-centered approach, which primarily places emphasis on the students' roles. Nevertheless, when comparing the benefits and disadvantages of incorporating peer feedback, many studies (Hu, 2005; Lam, 2010; Van Zundert et al., 2010) have reported its benefits have outweighed the impediments. As a result, there is no denying that peer feedback has many benefits in the development of ESL/EFL students to improve their written performance despite having some drawbacks. However, in order for peer feedback to be effective, peer training is a key component for teachers' consideration and planning how to train students more effectively to provide qualified feedback in the course of writing. 


\subsection{The Writing Process}

The process of the writing approach is not a new method, and this has been adopted since the early 1970s (Key, 1989). The development of writing skills has also encouraged the writer through the process from the beginning on to the eventual end product. More importantly, writing teachers need to understand how the writing process works so to have students practice to increase their problem-solving skills when they participate in each stage. In the study, the writing process consisted of six stages which were adapted from Flower and Hayes (1981), White and Arndt (1991) and Kim (2005)'s framework: 1) Preparation: Students were asked to compose a paragraph by generating ideas, mind mapping or making an outline, and using grammatical structure. 2) Drafting: Students conveyed all of their thoughts into the written paragraph. 3) Evaluation: Students conducted a peer group activity by evaluating their peers' work through discussion. 4) Interactive feedback: Students could immediately ask for clarification of the errors from their peers if they disagreed with the peers' response. 5) Reviewing: Students monitored their work by self-assessment. 6) Revising: Students were asked to rewrite a new paragraph including checking the grammar use and handwriting. After the revising stage, the students might go back and forth to the earlier stages with an attempt to revise and find more detailed information to perform the perfect task before submission. Therefore, it is believed that students ought to be introduced to the writing process and stimulated to improve their writing through prewriting with careful revision.

\section{Methodology}

\subsection{Research Design}

A mixed method research, an embedded experimental design, was adopted. The quantitative and qualitative data included the 36 items and the 6 open-ended questions adopted after the students had completed the peer feedback session to explore their attitudes toward the benefits and drawbacks of incorporating peer feedback in L2 writing.

\subsection{Subjects}

The subjects were 21 undergraduate students majoring in English in a tertiary writing class in a university in the three southernmost border provinces of Thailand. They had a prior English background because they had studied English writing courses comprising English Structure I, English Structure II, Writing I and Writing II. This implied that all students had sufficient English writing competence to provide feedback to their peers.

\subsection{Research Tools}

\subsubsection{The Peer Feedback Questionnaire}

The peer feedback questionnaire was divided into three parts: Part I involved students' personal information. Part II covered four domains including the 36 items; namely, the writing process, affective strategies, critical thinking skills and social interaction ability. Part III consisted of six open-ended questions to explore students' viewpoints toward the advantages and disadvantages of peer feedback. For the evaluation criteria, a five-point Likert scale with the options were "strongly agree, agree, neither agree nor disagree, disagree and strongly disagree", which were used to measure students' positive attitudes toward peer feedback based on the numbers 5 , $4,3,2,1$ where the statements marked "strongly agree" weighed at 5 while the statements marked "strongly disagree" weighed at 1 , respectively. The questionnaire was distributed to students after completing peer session.

\subsubsection{Validity and Reliability of the Instruments}

The peer feedback questionnaire was administered by three experts in the field of the English language in order to judge its congruence between the objectives and the questionnaire statements. The rated statements were calculated for the Index of Item-Objective-Congruence (IOC) as suggested by Rovinelli and Hambleton, (1977). Part I comprised the students' personal information. Part II was content validated at the rate of 0.78 from the calculation of the IOC of 36 items. Part III included six open-ended questions of peer feedback with the content validity at 0.89 , the intra-inter reliability had a high rating, and Spearman's Rho correlation coefficient was 0.88 . However, to ensure the reliability of the questionnaire, Cronbach's Alpha test was adopted to calculate the 30 students, and the results indicated that it was 0.94 with a high degree, which was considered acceptable.

\subsection{Data Collection}

At the beginning of the writing class, peer feedback training was administered to the students for approximately three weeks. To achieve this, students were effectively well-trained how to conduct the peer feedback process by providing and receiving feedback, writing strategies, using the peer feedback checklists, correcting five types of error codes, and learning about the roles of the students. The following eight weeks, they were asked to create their written drafts through conducting peer feedback discussion in a writing class and had to respond to the peer feedback questionnaire to reflect on what they had learned after the completion of peer feedback session. 


\subsubsection{Peer Feedback Training}

To ensure the quality of providing feedback, students were trained on how to give and receive feedback to peers. The concepts from Min's (2005) four-step procedure and Lam's (2010) peer feedback training were employed. Additionally, the lesson plan was adapted to the aims of the study to be appropriate for the context. Specifically, intensive peer training consists of three stages, which occurred in the first three weeks of the writing course.

Modeling Stage: First, the training session began with introducing the writing strategies and informing about the objectives of the use of peer feedback in a writing class. Later, the researcher explained about the advantages of utilizing peer feedback and shared about the objectives of the peer training, so that students would have adequate revising skills to create their tasks. Afterwards, the researcher introduced and demonstrated a four-step procedure: clarifying and identifying, explaining and giving suggestions, employing peer feedback checklists, and coding on five types of errors by using the samples of all the students.

Exploring Stage: Second, students were asked to practice some exercises about the four-step procedure and five types of errors by adopting the peer feedback checklists. This provided students with practicing the evaluation on how well the students understood the peer feedback materials and applied them. Afterward, students exchanged their tasks with their partners including marking peers' work and discussing the errors. Subsequently, seven students were interviewed about the benefits and disadvantages on peer feedback in an attempt to clarify their misunderstandings.

Consciousness-raising Stage: Students were asked to procude a narrative paragraph of approximately 150 words, and then they were asked to conduct a peer group discussion. Each student was responsible for two roles in the group feedback. As assessors, they provided feedback to assessees' work; as assessees, they received comments with suggestions from the assessors. Peer feedback occurred naturally, and if the assessees objected to the peer evaluation, they could immediately ask for more explanations and clarifications on the points that they did not understand from their peers. In the study, students were asked to form a small group of three students with mixed ability levels for greater participation and better productivity. To conduct effective peer feedback, peer training was employed to strengthen students' understanding about the process-based writing and peer feedback.

\subsection{Data Analysis}

In embedded designs, researchers begin with analyzing the quantitative and qualitative databases independently to align with the research question and then move to more integrative strategies as used in other common mixed method designs. It is conducted so that the secondary results complement and advocate a deeper understanding of the primary research question and results. In the current study, all four domains including the 36 questionnaire statements were analyzed by a dependent sample t-test, descriptive statistics was tabulated by the mean and standard deviation for each domain, and each statement of the questionnaire including the levels of the students' positive attitudes toward peer feedback which was abbreviated as (LPAPF), and the six open- ended questions were thematically analyzed.

\section{Results of the Quantitative Data}

The results of all four domains including the 36 questionnaire statements are presented as Domains 1-4, respectively.

Table 1. Questionnaire statements of Domain 1: "The Writing Process"

\begin{tabular}{|c|c|c|c|c|}
\hline Item no & Statements & $\mathbf{M}$ & SD & LPAPF \\
\hline 1 & $\begin{array}{l}\text { I received worthwhile experiences from doing peer } \\
\text { feedback. }\end{array}$ & 3.90 & 0.54 & High \\
\hline 2 & I could systematically conduct a peer group discussion. & 4.00 & 0.70 & High \\
\hline 3 & $\begin{array}{l}\text { I understand about the writing strategies in producing a } \\
\text { written paragraph. }\end{array}$ & 3.86 & 0.57 & High \\
\hline 4 & I could identify the paragraph structure of each genre. & 4.10 & 0.62 & High \\
\hline 5 & $\begin{array}{l}\text { I could understand how to construct the paragraph structure } \\
\text { of each genre. }\end{array}$ & 4.05 & 0.38 & High \\
\hline 6 & $\begin{array}{l}\text { I could develop my writing skills through peer feedback } \\
\text { more efficiently. }\end{array}$ & 4.14 & 0.36 & High \\
\hline
\end{tabular}




\begin{tabular}{llllll}
\hline 7 & I could expand the paragraph to be longer. & 4.29 & 0.56 & High \\
8 & $\begin{array}{l}\text { I could develop my writing ability, especially in the } \\
\text { content and organization. }\end{array}$ & 4.05 & 0.38 & High \\
$9 \quad \begin{array}{l}\text { I realized the students' roles as a provider and receiver in } \\
\text { conducting peer feedback. }\end{array}$ & 4.14 & 0.36 & High \\
& Average & $\mathbf{4 . 0 6}$ & $\mathbf{0 . 2 7}$ & High \\
\hline
\end{tabular}

As Table 1 illustrates, students had positive views toward peer feedback at a high rating on average $(\mathrm{M}=4.06$; $\mathrm{SD}=0.27)$ in the domain of the peer feedback process. The results presented that Item 7 received the highest mean score, which focused on students' improvement in expanding the paragraph writing to be longer $(M=4.29$; $\mathrm{SD}=0.56)$. This showed that students had developed their writing skills more effectively; furthermore, the importance of the students' roles in offering and receiving peer feedback was emphasized in Items 6 and $9(\mathrm{M}=$ 4.14; $\mathrm{SD}=0.36$ ). Then, students could efficiently learn the paragraph structure including identifying each kind of genre in Item $4(\mathrm{M}=4.1 ; \mathrm{SD}=0.62)$ and systematically conduct peer discussion in Item $2(\mathrm{M}=4 ; \mathrm{SD}=0.70)$. Students could also understand how to construct the paragraph writing of each genre in order to develop their written work in the aspects of the content and mechanics as Items 5 and 8 noted $(\mathrm{M}=4.05 ; \mathrm{SD}=0.38)$. Most importantly, after the peer feedback session, students obtained valuable experience in developing their writing at a high level as stated in Item $1(\mathrm{M}=3.9 ; \mathrm{SD}=0.54)$, and finally this was followed by students' understanding about learning the writing strategies with a high rating as shown in Item $3(\mathrm{M}=3.86 ; \mathrm{SD}=0.57)$.

Table 2. Questionnaire statements of Domain 2: "Affective Strategies"

\begin{tabular}{llllc}
\hline Item no & Statements & M & SD & LPAPF \\
\hline 10 & I was less anxious while giving feedback to peers' work. & 3.95 & 0.50 & High \\
11 & I was more confident in criticizing peers' work. & 4.10 & 0.62 & High \\
12 & $\begin{array}{l}\text { A peer group activity helped me reduce my stress in studying } \\
\text { writing. }\end{array}$ & 4.05 & 0.67 & High \\
13 & $\begin{array}{l}\text { My positive feelings helped me cope with my stress and anxiety } \\
\text { while offering feedback to peers. }\end{array}$ & 3.76 & 0.54 & High \\
14 & $\begin{array}{l}\text { I enjoyed interactional comments. } \\
\text { When there an argument occurred during the discussion, I could } \\
15\end{array}$ & 4.05 & 0.38 & High \\
16 & $\begin{array}{l}\text { control myself well and accept peers' different views. } \\
\text { Students' roles enthusiastically motivated me to engage in the } \\
\text { peer feedback activity. }\end{array}$ & 4.29 & 0.46 & High \\
17 & $\begin{array}{l}\text { As an assessor and an assessee, I could manage my emotions } \\
\text { well in the peer discussion. }\end{array}$ & 4.05 & 0.50 & High \\
18 & $\begin{array}{l}\text { When I disagreed with peers' opinions and rejected edited peer } \\
\text { correction, I explained to them reasonably as well as controlled } \\
\text { my emotions very well. }\end{array}$ & 4.10 & 0.30 & High \\
& $\quad$ High \\
& Average & $\mathbf{4 . 0 4}$ & $\mathbf{0 . 2 6}$ & High \\
\hline
\end{tabular}

As Table 2 presented above, the results illustrated that students had positive views toward conducting peer feedback with an overall high rating $(\mathrm{M}=4.04 ; \mathrm{SD}=0.26)$ in the domain of the affective strategies. Item 15 received the highest rating $(\mathrm{M}=4.29$; $\mathrm{SD}=0.46)$, which addressed that during the peer feedback discussion when there was an argument, students could manage their emotions to maintain the group work. They did not mainly focus on their own opinions, but accepted those of their peers. Furthermore, constant practice of doing peer feedback helped to build their confidence in criticizing peers' work. However, when they totally disagreed with their peers and rejected the edited mistakes, they conducted reasonable negotiation together. They accepted that peer feedback could make them learn how to cope with their negative feelings as shown in Items 11 and 18 $(\mathrm{M}=4.1 ; \mathrm{SD}=0.62$ and 0.30$)$. Moreover, students mentioned that a peer feedback activity helped decrease their 
stress in writing, and they enjoyed communicating with their peers. More importantly, they highlighted the significance of the students' roles, which motivated their interaction and helped them learn how to control their emotions in group work at a high rating as presented in Items $12,14,16$ and $17(\mathrm{M}=4.05 ; \mathrm{SD}=0.67,0.38,0.50$, and 0.38 ), respectively. As evidenced above, to reduce their anxiety in offering feedback to peers, having positive feelings is a crucial factor to enable students to eliminate the obstacles during dpeer feedback as demonstrated in Items 10 and $13(\mathrm{M}=3.95$ and $3.76 ; \mathrm{SD}=0.50$ and 0.54$)$.

Table 3. Questionnaire statements of Domain 3: "Critical Thinking Skills"

\begin{tabular}{|c|c|c|c|c|c|}
\hline Item no & Statements & & M & SD & LPAPF \\
\hline 19 & Peer feedback helped develop my critical thinking skills. & & 3.90 & 0.54 & High \\
\hline 20 & $\begin{array}{l}\text { Critical thinking skills assisted me to criticize peers' work } \\
\text { more efficiently. }\end{array}$ & & 3.86 & 0.65 & High \\
\hline 21 & $\begin{array}{l}\text { After conducting peer feedback, I could analyze and think } \\
\text { critically including having more self-awareness. }\end{array}$ & & 4.05 & 0.50 & High \\
\hline 22 & $\begin{array}{l}\text { Critiquing my peers' work helped develop my critical } \\
\text { thinking skills. }\end{array}$ & & 4.10 & 0.54 & High \\
\hline 23 & $\begin{array}{l}\text { Critical thinking skills were very crucial and necessary for } \\
\text { me in receiving the correct answer from my peers. }\end{array}$ & & 4.14 & 0.48 & High \\
\hline 24 & $\begin{array}{l}\text { Expressing and exchanging ideas helped me to judge my } \\
\text { peers' work more carefully as an assessor. }\end{array}$ & & 4.29 & 0.46 & High \\
\hline 25 & $\begin{array}{l}\text { The stages of evaluating and interactive feedback helped } \\
\text { me to practice critical thinking. }\end{array}$ & & 4.29 & 0.46 & High \\
\hline 26 & $\begin{array}{l}\text { As an assessee, I could debate when I did not accept peers' } \\
\text { different opinions. This helped me to practice evaluate my } \\
\text { peers' work. }\end{array}$ & & 4.24 & 0.44 & High \\
\hline \multirow[t]{2}{*}{27} & $\begin{array}{l}\text { Peer feedback was very helpful and beneficial in } \\
\text { developing critical thinking skills. }\end{array}$ & & 4.05 & 0.50 & High \\
\hline & & Average & 4.10 & 0.32 & High \\
\hline
\end{tabular}

As displayed in Table 3, the results showed that all of the questionnaire items averaged 4.1; $\mathrm{SD}=0.32$ at a high rating in the domain of critical thinking skills, and the first two highest ratings $(\mathrm{M}=4.29 ; \mathrm{SD}=0.46)$ were in Items 24 and 25. These items indicated that expressing and exchanging ideas helped students judge their peers' work more carefully, as well as helped increase their critical thinking skills when they conducted a peer group activity, especially in evaluating and interactive feedback. Then, the second highest mean scores were the assessee's roles. If students did not accept the peer response, they could immediately debate in order to ask for their peers' clarifications; two-way feedback also helped them to practice evaluate their peers' work as demonstrated in Item $26(\mathrm{M}=4.24 ; \mathrm{SD}=0.44)$. In particular, students agreed that critical thinking skills were necessary for them to obtain the correct answer from their peers as shown in Item 23 ( $M=4.14 ; \mathrm{SD}=0.48)$. This was in agreement with Item 22, which indicated that students were able to increase their critical thinking skills on the critique of their work $(M=4.10 ; \mathrm{SD}=0.54)$. Moreover, students' self-awareness was raised through the analytical and critical thinking skills. Consequently, peer feedback was one of the effective strategies to help students develop their critical thinking skills as illustrated in Items 21 and $27(\mathrm{M}=4.05$; $\mathrm{SD}=0.50)$. These issues were also addressed in Items 19 and 20 in which students' critical thinking skills were developed thought peers' critique $(\mathrm{M}=3.9$ and $3.86 ; \mathrm{SD}=0.54$ and 0.65$)$, respectively. 
Table 4. Questionnaire statements of Domain 4: "Social Interaction Ability"

\begin{tabular}{llllc}
\hline Item no & Statements & M & SD & LPAPF \\
\hline 28 & $\begin{array}{l}\text { I could develop my writing ability from group work more } \\
\text { effectively. }\end{array}$ & 4.14 & 0.36 & High \\
29 & $\begin{array}{l}\text { I have learned about collaborative learning strategy through a } \\
\text { peer group activity. }\end{array}$ & 3.95 & 0.67 & High \\
30 & $\begin{array}{l}\text { Discussing with peers enhanced my social interaction skills. } \\
\text { Peer feedback interaction assisted me to realize the roles as a } \\
\text { giver and a receiver. }\end{array}$ & 4.24 & 0.44 & High \\
32 & $\begin{array}{l}\text { Students' roles made me realize about taking responsibilities to } \\
\text { group members. }\end{array}$ & 4.10 & 0.54 & High \\
33 & $\begin{array}{l}\text { Peer feedback helped me learn about maintaining harmony in } \\
\text { group work. }\end{array}$ & 4.10 & 0.36 & High \\
34 & $\begin{array}{l}\text { Sharing ideas and listening to peers' opinions supported me with } \\
\text { social interaction skills. }\end{array}$ & 4.24 & 0.54 & High \\
35 & $\begin{array}{l}\text { When there was an argument occurring in interaction, I was able } \\
\text { to control the situation well in order to run a peer group activity } \\
\text { smoothly. }\end{array}$ & 4.24 & 0.44 & High \\
36 & $\begin{array}{l}\text { I realized individuals' differences in the aspect of their writing } \\
\text { ability through conducting peer feedback. }\end{array}$ & 4.29 & 0.56 & High \\
& Average & $\mathbf{4 . 1 6}$ & $\mathbf{0 . 2 8}$ & High \\
\hline
\end{tabular}

As can be seen in Table 4, the students had positive viewpoints toward employing peer feedback in developing their social interaction skills through an overall high rating at $\mathrm{M}=4.16 ; \mathrm{SD}=0.28$. The results clearly displayed that peer feedback helped enhance students' social dimension through interaction. The first highest rating was in Item 36, which focused on the differences of the individuals' writing ability $(\mathrm{M}=4.29 ; \mathrm{SD}=0.56)$. Moreover, students highlighted that interacting with peers, sharing ideas and listening to peers' views helped enhance their social interaction skills with learning how to solve the problems in group work as demonstrated in Items 30,34 and $35(\mathrm{M}=4.24 ; \mathrm{SD}=0.44,0.54$, and 0.44). In addition, students addressed that an improvement in writing could be developed through doing peer feedback, and students' roles increased their responsibilities to group members in Items 28 and $32(\mathrm{M}=4.14$; $\mathrm{SD}=0.36)$. Students stressed that the roles of students in peer feedback helped them realize about being both a feedback giver and a feedback receiver. For instance, when there was a debate occurring in the discussion, they attempted to eliminate the difficulties in order to maintain group cohesion and harmony in doing a peer group activity as Items 31 and 33 mentioned $(\mathrm{M}=4.10 ; \mathrm{SD}=0.54)$. Finally, students added that they had a better understanding about social collaborative learning through the peer feedback activity as seen in the high rating in Item $29(\mathrm{M}=3.95 ; \mathrm{SD}=0.67)$.

\subsection{Results of the Qualitative Data}

Triangulation was adopted to increase the validity and reliability of the findings. To elaborate, if the results of the questionnaire survey with the 36 questionnaire statements corresponded to the results of the qualitative data of the 6 open-ended questions on the same phenomena, this would increase the belief in the research findings (Creswell, 2011). In this study, the results revealed that the students had high positive viewpoints toward peer feedback in the writing class. There were three main themes extracted from the data analysis; namely, benefits and obstacles of peer feedback, the implemented peer feedback pedagogy with the subthemes, and its category including a frequency count and percentages as presented in Table 5. 
Table 5. Students' attitudes towards peer feedback activity

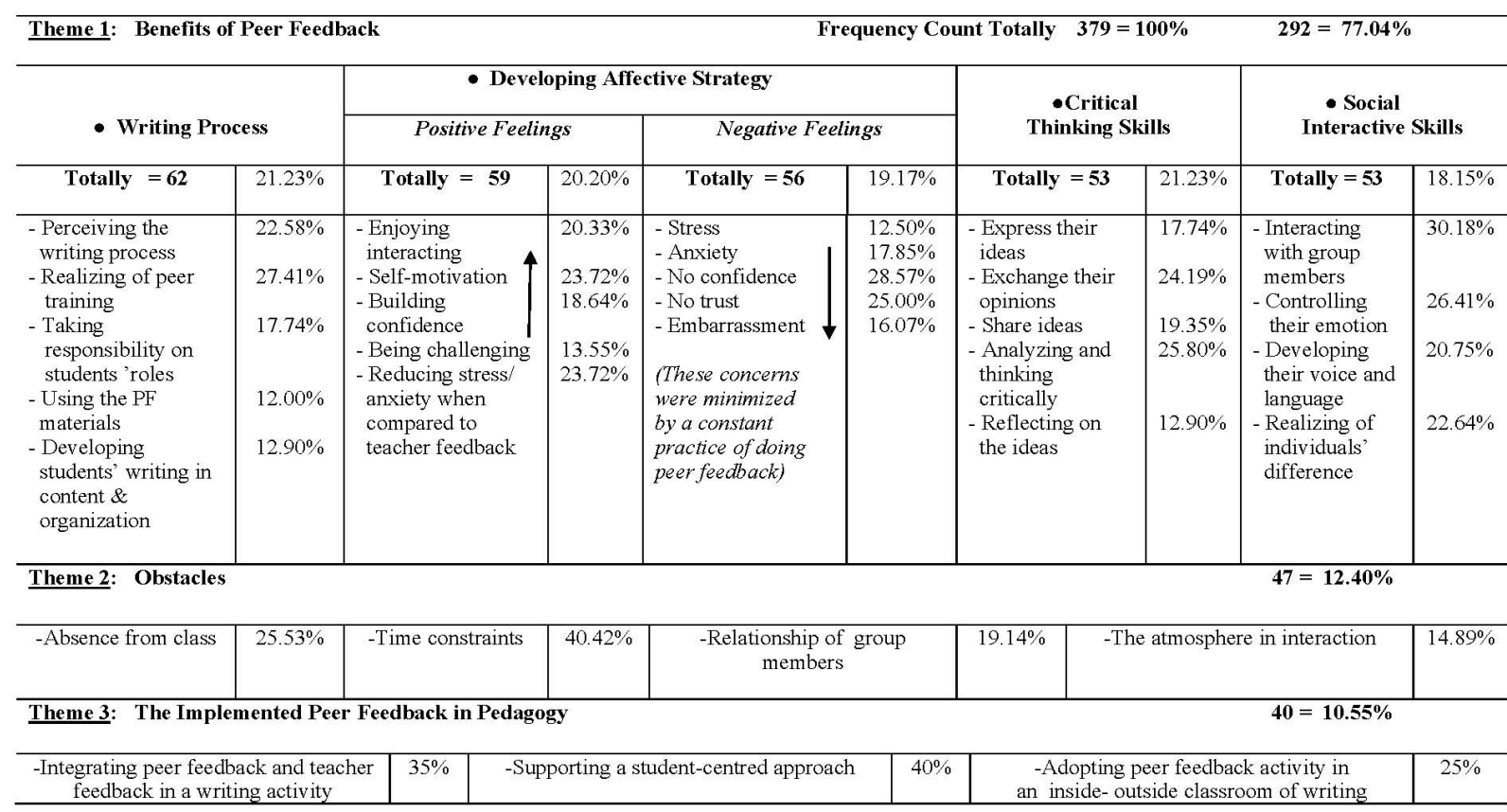

The first theme was directly related to the benefits of peer feedback covering four subthemes: the writing process, affective strategies, critical thinking skills and social interaction skills. The overall findings reported that $77.04 \%$ of students could develop their writing skills more effectively through peer feedback. This is explained in details as follows:

With respect to the writing process, the overall findings illustrated that students understood about process-based writing $(21.23 \%)$. It also indicates that they perceived the writing and peer feedback process $(22.58 \%)$; moreover, they emphasized on the importance of peer feedback training $(27.41 \%)$, realized of their roles $(17.74 \%)$, adopted peer feedback materials $(12.00 \%)$, and developed their compositions through peer correction $(12.09 \%)$.

With regards to affective strategies, this domain was divided into two issues: positive and negative feelings. The overall results indicated that students had positive feelings about adopting peer feedback (20.20\%). For example, students mentioned that they enjoyed interacting with peers $(20.33 \%)$, and working in groups encouraged them to be involved in the activity (23.72\%). Moreover, students felt the challenge of their English writing ability to peers $(8 \%)$ and raised self-confidence $(18.64 \%)$. Nonetheless, students addressed that constant practice of doing peer feedback reduced their negative feelings $(19.17 \%)$ such as stress $(7 \%)$, anxiety $(10 \%)$ and embarrassment $(9 \%)$ in learning. On the other hand, it helped increase self-confidence $(16 \%)$ and credibility among peers (14\%). As aforementioned, peer feedback is also a good teaching method for students in developing affective strategies.

Another issue involved the critical thinking skills where the overall findings showed that students enhanced their critical thinking skills in peer discussion $(21.23 \%)$. A majority of the students agreed that peer feedback helped them practice expressing the ideas (17.74\%), exchanging the opinions $(24.19 \%)$, sharing ideas including solving problems (19.35\%), raising analytical and critical thinking (25.80\%), as well as reflecting their views (12.90\%). As claimed above, peer feedback is a problem-solving activity which helps support their critical thinking skills.

Regarding the social dimension, from the overall findings (18.15\%), students accepted that a peer group activity helped enhance their social skills. This indicates that interacting with peers helped foster students' skills of social interaction (30.18\%), and importantly they could learn how to control their emotions through collaboratively working in groups (26.41\%); additionally, they addressed that they had learned how to reasonably negotiate and compromise through voice and language in communication (20.75\%). More importantly, realizing the difference of individuals' English writing ability was important in maintaining the group work (22.64\%). As noted above, peer feedback is a worthwhile experience for social interaction.

The second theme referred to the obstacles during conducting peer feedback. The results demonstrated that from the overall findings, $12.40 \%$ of the students confronted the obstacles. Moreover, students noted that absenteeism (25.53\%), time limitations (40.42\%), group relationship (19.14\%), and the atmosphere in the interaction (14.89\%) 
impacted on their offering and receiving feedback. Nevertheless, though some concerns occurred in doing peer feedback, as mentioned earlier, peer feedback is beneficial for students in improving their writing.

The last theme focused on the implemented peer feedback in pedagy, which covered three subthemes: suitability in peer feedback use in teaching writing, supporting a student-centered method and adopting peer feedback in an inside-outside class. The overall findings of the last theme revealed that utilizing peer feedback enabled them to improve their written performance more efficiently $(10.55 \%)$, and it was also considered to be a student-centered approach (35\%). Moreover, they added that peer feedback was a practical and suitable activity $(40 \%)$, which should be adopted in an inside-outside classroom of writing $(25 \%)$.

\section{Discussion}

This utilized qualitative data through six open-ended questions and quantitative data by the means of a five-point Likert scale questionnaire in an attempt to gain a more comprehensive understanding by investigating the role of a qualitative strand in a mixed methods research (Creswell, 2011). From the analysis of the collected data, the results indicated that students had positive viewpoints toward providing feedback with peers by receiving a high rating of all four domains in terms of the writing process, affective strategies, critical thinking skills, and social interaction skills after the peer feedback session.

\subsection{The Writing Process}

Students appreciated the worthwhile experiences about adopting the writing process in producing their tasks. The results revealed that students perceived the process-based writing and peer feedback process. Moreover, they developed their writing skills, especially in the content and organization, and importantly, they were more skilled in how to employ the peer feedback materials in evaluating peers' tasks. Moreover, peer feedback process helped encourage them to be more involved in the activity through the roles of a feedback giver and feedback receiver. This created their responsibilities for learning and being peer group members, and significantly they mentioned that peer feedback training immensely impacted on their abilities in correcting peers' work and discussing with their peers. Moreover, these also concurred to Min's (2005) and Shehadeh's (2011) studies, which highlighted about the positive effects of students' viewpoints toward using peer feedback with their writing improvement by focusing on content and organization rather than the grammar and mechanics. In addition, the roles of students in peer feedback helped them shoulder much responsibility because they spent a great deal of time reading in order to provide feedback to their peers, and this was also supported by the results of the questionnaire in the writing process (Domain 1), which reported that students had an in-depth understanding on how to use the approach of the writing process in generating their compositions at a high level. They understood about the writing strategies in producing a paragraph structure of each genre, developed their ideas in expanding the text within an allocated time, systematically conducted a peer group activity, and realized their own duties.

Moreover, the crucial factor which resulted in students' writing improvement was influenced by intensive peer feedback training. The findings illustrated that peer feedback training helped them perceive the writing strategies and peer feedback from the starting stage to the final drafts as a whole process. Besides, prior research confirmed that peer feedback training has its positive effects on improving students' writing skills. These were evidenced by a number of empirical studies that had been conducted to investigate the effects of peer feedback training on developing students' writing abilities (Goldberg, 2012; Hu, 2005; Liou \& Peng, 2009; Khalil, 2018; Kunwongse, 2013; Nguyen, 2016), and the results showed that peer training importantly affected students' incorporation of peer correction into the text revisions and increased their writing quality. Furthermore, it raised their competence to provide better written commentaries and built self-confidence in their writing. Furthermore, this concurred with Min's (2005) study, which revealed that students who are well-trained in doing peer feedback can produce better tasks. Specifically, they provide qualified comments by finally clarifying more specific grammatical areas. Consequently, it could be concluded that by having well-managed peer feedback is an important indicator to measure students' success or failure of using peer feedback to develop their writing.

\subsection{Affective Strategies}

It is accepted that students can develop affective strategies through peer group discussion. Peer feedback created an interactional enjoyment, stimulated them in group feedback, and built self-confidence on the critique of peers' tasks. Notably, this was in agreement with Khalil's (2018) study, which found that peer feedback has positive effects in the sense of increasing self-motivation and improving self-confidence from the criticism of peers' tasks. In addition, the findings supported the results of Tui and Ngo's (2000) study, which claimed that peer feedback stimulates students to participate in the activity, builds confidence and makes them become more independent learners without relying on the teacher and boosting self-confidence as writers. Moreover, this challenged their writing competence by comparing with peers in an attempt to develop their work and decreased their writing 
anxiety. However, although they still had some negative feelings in doing a peer group activity from the start, praciting peer feedback every week assisted them to lessen their negative emotions.

This also conformed to the findings presented in the questionnaire of the affective strategies (Domain 2), which revealed that students developed their affective strategies at a high rating by incorporating peer feedback. It also indicates that peer feedback minimized students' stress and anxiety and maximized self-confidence. Moreover, the majority of the students noted that having positive feelings was a crucial factor while commenting on peers' tasks. Practicing peer feedback helped increase confidence to revise the compositions. In addition, they enjoyed their interactional comments. Nevertheless, when an argument took place during the discussion, they controlled their feelings well and learned how to accept criticism or reject different views and pay more attention to peer critiquing. Furthermore, the roles of the students encouraged them to the activity. As mentioned above, positive feelings in doing peer feedback create a relaxing and friendly atmosphere to the peer group and actively inspires students to the activity participation, and it also raises their self-awareness, self-motivation and self-confidence.

\subsection{Critical Thinking Skills}

With respect to critical thinking skills, it is accepted that discussing among peer group members helps reinforce students' critical thinking abilities. Apparently, peer feedback process advocates students to express their ideas, exchange thier views, share their ideas, and critically think about peers for reaching a consensus. Students have also learned about the experience on how to be self-reflective. Peer feedback eases their thoughts in generating ideas, and it involves them in reading different formats of thinking and arguing on the same topic. This was also in agreement with Brusa and Harutyunyan's (2019) study, which claimed that peer feedback supports students to become an effective autonomous learner and a more critical thinker; moreover, they can learn about their own strengths and weaknesses from correcting by peers to obtain a better written performance (Nguyen, 2016; Tsui and $\mathrm{Ng}, 2000$ ). In addition, reading fluently and thinking critically in peer discussion makes students become readers, critics and eventually evaluators as Rollinson (2005) noted. As such, offering feedback by peers helps them receive logical and fruitful comments in improving their subsequent tasks, and eventually practicing peer evaluation helps increase their critical thinking skills to become a better critical thinker and a responsible learner.

This also corresponded to the findings of the questionnaire in critical thinking skills (Domain 3), which revealed that students' critical thinking abilities could be increased by means of the critique on peers' tasks. To illustrate, this assisted students to develop their critical and analytical thinking skills by means of criticizing peers' tasks through the evaluating and interactive feedback. For instance, peer feedback practices student writers to analyze and think critically provided that student readers need their clarifications and explanations, and self-awareness of their weakness is raised by reading peers' tasks. Importantly, this provides students with more opportunities in expressing opinions, exchanging ideas with one another, and discussing problematic areas with an attempt to solve the problems. Consequently, increasing critical thinking skills can be practiced by doing peer discussion.

\subsection{Social Interaction Ability}

Peer interaction is defined as a form of cooperative and collaborative learning, which helps reinforce students' social interaction ability. After the training, working in groups by doing peer feedback made students learn to be more aware of their different individuals' English writing ability. Additionally, using voice and language was a crucial factor to deliver their intended messages and to establish a relaxed and friendly atmosphere among group peer members. In particular, they could control their emotions well in the way of learning how to negotiate and compromise appropriately through interaction. This was also supported by the results of the questionnaire in social interaction skills (Domain 4), which showed that peer feedback reinforced students' social interaction abilities as seen by the overall high rating. This indicates that the students developed their social skills by making use of peer interaction, and more importantly, peer interaction helped them take much responsibility for their roles as both a feedback giver and a feedback receiver. In addition, accepting peers' different views helped to maintain group cohesion and harmony. In addition, providing feedback by peers assists students to develop their performance and learn about peers' written tasks. This also corresponds to Vygotsky's (1978) approaches that highlight the importance of social interaction as "the Zone of Proximal Development", which suggests that learning strategies can be developed in the ways of others' guidance and assistance. Furthermore, peer feedback stresses the social context and social interactions in creating a better understanding of the learning strategies through problem-solving activities, and it also helps students enhance their language learning including writing and grammar through the role of students as both a feedback giver and receiver. This implied that they shoulder much of their responsibilities in the peer group feedback in providing constructive and supportive feedback (Allharbi, 2019; Kunwogse, 2013; Min, 2016; Nguyen, 2016). There is no doubt that peer feedback provides students with valued experiences in social dimension in the sense of taking much responsibilities on their own 
duties to group peer members by working collaboratively.

\subsection{The Obstacles of Peer Feedback}

In referring to students' obstacles in using peer feedback, it is accepted that there were still some concerns which they confronted in group feedback; 1) Absenteeism resulted in the failure of conducting peer feedback. 2) Time allocation was caused by providing qualified feedback, for the students remained unfamiliar with peer feedback such as using peer feedback materials; otherwise, they were not skillful in correcting the mistakes by making use of the five types of error codes. 3) The relationship of group peer members impacted on students' providing and receiving feedback on peers' tasks. A few students accepted that it was rather difficult to give honest feedback to distant friends because they were afraid that their peers would not accept the peer evaluation, and they preferred to avoid peers' conflict or disputation. Eventually, 4) The unfriendly atmosphere in interaction occurred through showing a negative facial reaction.

However, constant practice of doing peer feedback can decrease these obstacles. 1) The roles of students in peer discussion create their responsibility to conduct effective peer feedback. 2) Practicing peer feedback every week encourages their learning strategies. This means that they would be more familiar with adopting peer feedback materials to correct the errors. 3) Working in peer groups builds a closeness of the relationship to the members, so they dare to give truthful feedback and to criticize peers' tasks. 4) A secure and collaborative environment in peer interaction would be effective through appropriate use of the voice and language. In this study, students learned how to suitably negotiate and compromise to reach a consensus through maintaining group cohesion. Likewise, their voice was clearer with an appreciative volume to the audience. Additionally, discussing among peer members was conducted smoothly and effectively through their positive reactions and their willingness in offering and obtaining feedback. Therefore, it should be mentioned that students could deal with these problems with an attempt to conduct peer feedback more effectively. This was also supported by Grabe and Kapan's (1996: 379) study, which stated that a peer group activity enhances students 'learning together', and the peer feedback process helps students learn how to use language for responding to texts. Besides, peer feedback is a cooperative and collaborative learning which helps students develop intrinsic motivation physically and mentally in learning through sharing information and their effort to achieve their tasks, develop trust with their peers, and to be in charge of their participative roles in the activity (Frey \& Fisher, 2010; Olsen \& Kagan, 1992; Oxford, 1997; Williams \& Williams, 2012, as cited in Kunwonges, 2013). As a result, conducting peer feedback continuously changes students' behavior into learning motivation.

However, although students confronted some difficulties in doing peer feedback, most of them agreed that peer feedback and teacher feedback ought to be integrated in L2 writing class, and it also supports a student-centered method with an emphasis on the significance of students' roles via the whole process. Moreover, peer feedback should be sometimes employed in an inside-outside classroom as suggested by students in the findings of the open-ended questions.

Consequently, students improved their English writing competence more effectively by having highly positive viewpoints toward adopting peer feedback as shown in the findings earlier. Other positive outcomes may be due to planning the lesson, practicing paragraph writing regularly, and doing peer feedback continuously; likewise, students could broaden the usefulness of the learning strategies, and make use of peer feedback to listening, speaking and reading skills, or other relevant fields. Nevertheless, it is recommended that this study should be conducted for a longer period of time or maintained throughout the semester to strengthen the findings, and for further studies, a close small group of the sampling should be taken into account in the issue of generalization.

\section{Conclusion and Implications}

As peer feedback is one of the most dynamic ways of teaching, this study made an attempt to put forward some tremendous advantages of utilizing peer feedback toward the students in L2 writing. The results indicated that students had positive attitudes toward using peer feedback at an overall high level in terms of the writing process, affective strategies, critical thinking skills, and social interaction skills. To achieve this, one of the pivotal factors in doing peer feedback is the training. Obviously, obtaining a good process generates effective products and/or results. Therefore, the peer feedback process helps students become more skillful in academic English writing. Additionally, peer feedback helps students develop learner autonomy in writing. More importantly, the findings provide both pedagogical and theoretical implications in teaching writing. In pedagogy, peer feedback can be applied to the writing contexts to strengthen self-reliant students in learner-centered classrooms by means of providing students with collaborative learning including developing both socially and intellectually. In theory, the study confirmed the students' positive attitudes toward incorporating peer feedback to improve their writing ability. Accordingly, peer feedback should be implemented in L2 writing with an attempt to develop students' 
positive attitudes toward process-based writing and their writing efficiency.

\section{References}

Ahmadain, M., \& Tajabadi, A. (2017). Patterns of interaction in young EFL learners' pair work: The relationship between pair dynamics and vocabulary acquisition. The Southeast Asian Journal of English Language Studies, 22(3), 98-114. https://doi.org/10.17576/3L-2017-2301-08

Allharbi, M. A. (2019). Patterns of EFL learners' and instructor's interactions in asynchronous group discussion on free writing. Arab Society of English Language Studies. https://doi.org/10.28945/4143

Berg, E. C. (1999). The effects of trained peer response on ESL students' revision types and writing quality. Journal of Second Language Writing, 8(3), 215-41. https://doi.org/10.1016/S1060-3743(99)80115-5

Berkenkotter, C., \& Huckin, T. (1995). Genre knowledge in disciplinary communication: Cognition/ culture/power. Hillsdale, NJ: Lawrence Erlbaum. https://doi.org/10.2307/358302

Bosboom, R., Goff, M, Isherwood, L., \& Haan-de-Knot, R. (2014). Relationship between attitude towards peer review and quality of peer feedback. Practice Based Research, U-TEAch program, Utrecht University.

Brusa, M., \& Harutyunyan, L. (2019). Peer review: A tool to enhance the quality of academic written productions. English Language Teaching, 12(5). https://doi.org/10.5539/elt.v12n5p30

Chang, C. Y. H. (2016). Two decades of research in L2 peer review. Journal of Writing Research, 8(1), 81-117. https://doi.org/10.17239/jowr-2016.08.01.03

Corbin, B. (2012). Improving L2 peer-feedback. Retrieved from www.bryancorbin.net/.../2012/.Improving-L2-P.

Creswell, J. W. (2011). Controversies in Mixed Methods Research. In N. Denzin, \& Y. S. Lincoln (Eds.). The Sage Handbook of Qualitative Research (4th ed., pp. 269-283). Thousand Oaks, CA: Sage Publications.

Farrah, M. (2012). The impact of peer feedback on improving the writing skills among Hebron University students. An-Najah University Journal for Research, 26(1), 179-210

Flower, L. S., \& Hayes, J. R. (1981). A cognitive process theory of writing. College Composition and Communication, 32, 365-387. https://doi.org/10.2307/356600

Goldberg. (2012). ESL students' perceptions of their English writing. Proficiency and the effects of peer review training among three types of students in a community college ESL composition course Ph.D. dissertation, Alliant International University.

Grabe, W., \& Kaplan, R. B. (1996). Theory \& practice of writing. Communication, 32, 365-387.

Halliday, M. A. K. (1978). Language as a social semiotic: The social interpretation of language and meaning. London and Boston: Edward Arnold.

Hansen, J. G., \& Liu, J. (2005). Guiding principles for effective peer response. ELT Journal, 59(1), 31-38. https://doi.org/10.1093/elt/cci004

Hirose, K. (2008) Cooperative learning in English writing instruction through peer feedback. Retrieved from jasce.jp/conf05/hirosepaper.doc

Hyland, K., \& Hyland, F. (2006). Feedback on second language students' writing. Lang. Teach., 39, 77-95. https://doi.org/10.1017/S0261444806003399

Hyland, F. (2000). ESL writers and feedback: Giving more autonomy to students. Journal of Language Teaching Research, 4(1), 33-54. https://doi.org/10.1177/136216880000400103

Hu, G. W. (2005). Using peer review with Chinese ESL student writers. Language Teaching Research, 9 , 321-342. https://doi.org/10.1191/13621688051r169oa

Keh, C. (1989). Teaching proofreading: Analysis, diagnosis and production. Paper presented at the RELC Conference (Singapore).

Khalil, E. (2018). The efficacy of peer feedback in Turkish EFL students' writing performance: Journal of Literature and Art Studies, 8(6), 920-931. https://doi.org/10.17265/2159-5836/2018.06.011

Kim, M. (2005). Peer Assessment as a Learning Method. The Effects of the Assessor and Assessee's Role on Metacognitive Awareness, Performance, and Attitude.

Kunwongse, S. (2013). Peer Feedback, Benefits and Drawbacks. Thammasat Review.

Lam, R. (2010). A peer review training workshop: Coaching students to give and evaluate peer feedback. TESL 
Canada Journal, 27(2), 114-127. https://doi.org/10.18806/tesl.v27i2.1052

Leki, I. (1991). The preference of ESL students for error correction in college-level writing classes. Foreign Language Annals, 24, 203-218. https://doi.org/10.1111/j.1944-9720.1991.tb00464.x

Liou, H. C., \& Peng, Z. Y. (2009). Training effects on computer-mediated peer review. System, 37, 514-525. https://doi.org/10.1016/j.system.2009.01.005

Liu, N., \& D. Carless. (2006). Peer Feedback: The Learning Element of Peer Assessment. Teaching in Higher Education, 11(3), 279-290. https://doi.org/10.1080/13562510600680582

Liu, J., \& Hansen, J. G. (2002). Peer response in second language writing classrooms. Michigan: University of Michigan Press. https://doi.org/10.3998/mpub.8952

Lu, J., \& Law, N. (2012). Online Peer Assessment: Effects of Cognitive and Affective Feedback. Instructional Science: An International Journal of the Learning Sciences, 40(2), 257-275.

Mendoca, C., \& Johnson, K. (1994) Peer review negotiations: Revision activities in ESL writing instruction. TESOL Quarterly, 28(4), 745-768. https://doi.org/10.2307/3587558

Min, H. T. (2005). Training students to become successful peer reviewers. System, 33(2), 293-308. https://doi.org/10.1016/j.system.2004.11.003

Min, H. T. (2016). Effect of teacher modeling and feedback on EFL students' peer review skills in peer review training. Journal of Second Language Writing, 31, 43-57. https://doi.org/10.1016/j.jslw.2016.01.004

Nguyen, H. T. (2016). Peer Feedback Practice in EFL Tertiary Writing Classes. English Language Teaching, 9(6), 76-91. https://doi.org/10.5539/elt.v9n6p76

Rahmat, R.B. (2013) Peer feedback: a case study of assessment for learning in a Singaporean classroom. Proceeding of the Global Summit on Education (GSE2013). Organized by World Conferences.net.

Reynolds, A. (2009). Why Every Student Needs Critical Friends. Educational Leadership, 67 (3), 54-57.

Rollinson, P. (2005). Using peer feedback in the ESL writing class. ELT Journal, 59(1), 23-30. https://doi.org/10.1093/elt/cci003

Rovinelli, R. J., \& Hambleton, R. K. (1977). On the use of content specialists in the assessment of criterion-referenced test item validity. Dutch Journal of Educational Research, 2, 49-60.

Stanley, J. (1992). Coaching student writers to be effective peer evaluators. Journal of Second Language Writing, 1(3), 217-33. https://doi.org/10.1016/1060-3743(92)90004-9

Torwong, P. (2003). Peer Response Technique: A Proposed Model for EFL Writing. Unpublished Ph.D. Dissertation, Suranaree University of Technology.

Tsui, A. B. M., \& Ng, M. (2000). Do secondary L2 writers benefit from peer comments? Journal of Second Language Writing, 9(2), 147-170. https://doi.org/10.1016/S1060-3743(00)00022-9

Van Zundert, M., Sluijsmans, D., \& Van Merriënboer, J. (2010). Effective peer assessment processes: Research findings and future directions. Learning and Instruction, 20, 270-279. https://doi.org/10.1016/ j.learninstruc.2009.08.004

Vygotsky, L. S. (1978). Mind in society: The development of higher psychological processes. Cambridge: Harvard University Press.

White, R., \& Arndt, V. (1991). Process Writing. London: Longman.

Zhu, W. (2001). Interaction and feedback in mixed peer response groups. Journal of Second Language Writing, 10, 251-276. https://doi.org/10.1016/S1060-3743(01)00043-1

\section{Copyrights}

Copyright for this article is retained by the author(s), with first publication rights granted to the journal.

This is an open-access article distributed under the terms and conditions of the Creative Commons Attribution license (http://creativecommons.org/licenses/by/4.0/). 